\title{
The role of entrepreneurship in transforming efficiency economies into innovation-based economies
}

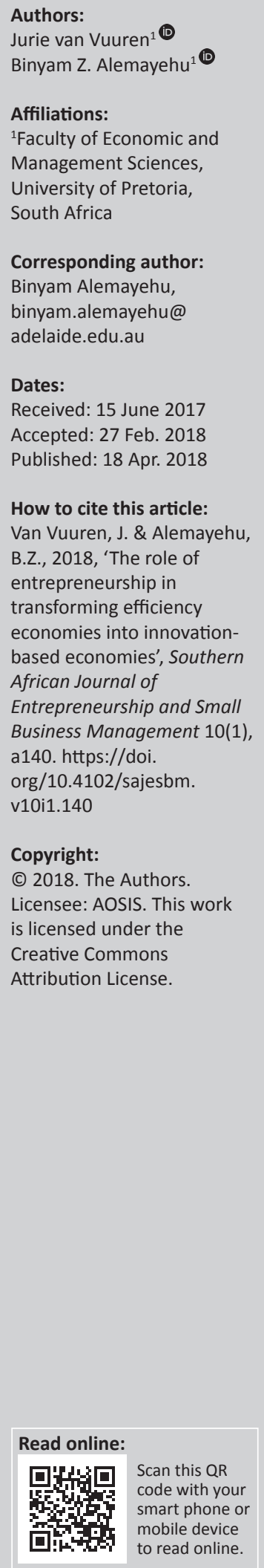

Background: Entrepreneurship is believed to be a major driver of economic development. While it is right to consider entrepreneurship as a development tool, it is also crucial to identify the kind of entrepreneurship that contributes meaningfully towards economic development. Extant research revealed a U-shaped relationship between entrepreneurship and economic development and claimed that entrepreneurship in efficiency economies is dwarfed in terms of its contribution to economic development.

Aim: To identify and explain factors that would assist efficiency-based countries to transform their economies using entrepreneurship as a major policy tool.

Setting: We compared two structurally separate groups of countries. Each group consists of three countries and 9 years of data were extracted from Global Entrepreneurship Monitoring (GEM) and United Nation (UN) datasets.

Methods: We examined the relationship between entrepreneurship and economic development using comparative research design. Bivariate correlation analysis was used to detect associations and various descriptive statistical tools were applied to examine and compare the entrepreneurial tendencies of countries included in our study.

Results: The results indicated that entrepreneurship in efficiency economies is unfairly undervalued by academic commentators and that our findings pose a serious question as to the U-shaped relationship argument. The analysis revealed that the relationship between entrepreneurship and economic development is positive in both contexts, albeit the strength of the correlation is much more pronounced for innovation-driven economies compared to efficiency-driven countries. Furthermore, the analysis revealed that the rate of total early-stage entrepreneurial activity (TEA) is strongly correlated with perceived opportunity and entrepreneurial intention scores in both contexts.

Conclusion: It is concluded that countries seeking to transform their economy need to promote the emergence and sustenance of TEA through well-designed policy frameworks and initiatives.

\section{Introduction}

Entrepreneurship has attracted substantial interest from different parties and is regarded as an engine of economic growth (Albulescu \& Tămăşilă 2016; Chowdhury, Terjesen \& Audretsch 2015). It sets out a robust platform for economic development through triggering innovation, job creation, productivity, and economic and social growth (Driga, Lafuente \& Vaillant 2009; Johnson, Freeman \& Staudenmaier 2015; Thornton, Ribeiro-Soriano \& Urbano 2011; Wennekers et al. 2010).

Entrepreneurship serves both as an engine driving economic growth and a strategy that promotes the discovery, dissemination and application of innovative ideas. By so doing, it aims at ensuring efficient utilisation of resources and expanding the boundaries of economic activities (OECD 1998) while serving as a conduit for a spillover of knowledge that leads to the shifting of resources towards more productive activities (Bruton, Ahlstrom \& Si 2015).

Moreover, various studies have also shown an inherent relationship existing between entrepreneurship and forces that shape economic prosperity. Galindo and Méndez (2014), for instance, identified a virtuous cycle type of relationship between innovation, entrepreneurship and economic growth in which all the variables exert positive effects on one another. Improving one of the factors could induce a positive change in another. On a different but related note, Pech (2016) asserted that innovation triggers a competitive edge in technology, design engineering and entrepreneurship. He also alluded to the reverse relationship that exists between entrepreneurship and innovation. 
Given the above-mentioned robust relationship between entrepreneurship and economic development and the positive connotation associated with entrepreneurship, economies across the world have given considerable attention to the development and proliferation of entrepreneurial activities. However, despite strong support from various stakeholders, countries still fail to maintain comparable levels of entrepreneurial activity (Hechavarría 2016; Pinillos \& Reyes 2011). The disparity between developed and developing countries, in particular, is rather large and persistent. Conventionally, it is innovation-based countries that record stronger and better quality entrepreneurial activities than any other economies, including efficiencydriven economies (Baptista \& Thurik 2007).

Researchers who attempted to explain this disparity identified an array of causes including quality of entrepreneurship (Baumol \& Strom 2007), economic conditions, legal and tax frameworks (Yolaç 2015), culture (Linan \& Fernandez-Serrano 2014; Pinillos \& Reyes 2011) and the quality of education (Guerrero, Urbano \& Fayolle 2016) On the other hand, efficiency economies are known for their less friendly entrepreneurial environment and rampant structural barriers stifling the growth of the sector.

Despite entrepreneurship in efficiency economies not being well-developed, we cannot repudiate its contribution to the economic development of those nations (Stam \& Stel 2009). However, we contend that if such economies were cognisant enough about the challenges that entrepreneurs are facing and more able to provide a hospitable entrepreneurial environment, the contribution would have been much better than what we see today.

Therefore, in this article we argue that efficiency economies could make much more of their entrepreneurship by encouraging more people to identify entrepreneurial opportunities and pursue their entrepreneurial intention. We identified a moderate correlation between total early-stage entrepreneurial activity (TEA) and gross domestic product (GDP) in efficiency economies and, from what we have seen in innovation-driven countries, this association could improve if greater numbers of opportunity entrepreneurs with high-growth potential were to be supported. In the conclusion and discussion sections, we have provided practical guidelines and inputs for policymakers regarding how that might be achieved.

By furnishing these, the current study fills the gaps in the existing literature. Despite the strong urge to explicate how an efficiency economy could build an innovation-centred economy, extant research has focused excessively on studying the relationship between entrepreneurship and economic development and the peculiarities of entrepreneurship in each setting. To the best of our knowledge, no prior research has investigated the association between entrepreneurship and economic development using two structurally different economies and described how the less developed economy can improve to a highereconomiclevelusing entrepreneurship as a major enabling tool. This makes our study unique amongst existing studies.

We utilised the World Economic Forum (WEF) countries' economic categorisation in order to create the two sets of economies (innovation-driven and efficiency-driven economies). The USA, UK and Germany were the three sample states chosen to represent the innovation-driven economies, whereas the efficiency-driven economies group was represented by China, Brazil and South Africa. Economic development was measured by GDP, while the entrepreneurial dynamics were measured and represented by TEA rates. In addition, the perception of opportunity and entrepreneurial intention scores of each country were correlated with TEA rates of the sample countries to identify factors that influence entrepreneurial activities using 9 years of GEM data.

The article is structured as follows. The next section provides findings from extant literature and subsequently presents the resulting hypotheses. In the 'Methodology' section, the methodology of the research is discussed, while the final part elucidates the results of the analysis, discussion and limitations and offers recommendations for future research.

\section{Literature review and hypotheses Entrepreneurship and economic development}

Entrepreneurship plays a critical role in national and regional economic development (Linan \& Fernandez-Serrano 2014; Matejovsky, Mohapatra \& Steiner 2014). Entrepreneurship, as a driver of an economy, determines the prospects of the economy and sets the pace of economic growth through creating employment opportunities, spurring innovation, facilitating effective and creative ways of utilising resources, expanding and extending economic boundaries and, ultimately, improving social welfare and growth (Driga et al. 2009; Johnson et al. 2015; Thornton et al. 2011; Wennekers et al. 2010).

Notwithstanding the advantages that entrepreneurship provides to economic growth, there is a concern about the kind of entrepreneurship that countries need to promote. Research has attested that the contributions of different kinds of entrepreneurship vary from one economy to another (Vallierea \& Peterson 2009).

Apparently, meaningful early entrepreneurial activities are stronger in well-developed economies than in economies in transition or efficiency-driven economies. Researchers found that the significant investments in research and development, strong technological environments and robust economic standards of innovation-driven economies enabled them to create entrepreneurs with high impact (Colovic \& Lamotte 2015). As a result, they enjoy an abundance of high-impact technological entrepreneurs to a greater extent than economies dominated by necessity entrepreneurs. This creates a formidable basis for new entrepreneurs to meaningfully contribute to their country's economic development (Koster \& Rai 2008; Pfeifer \& Sarlija 2010). 
According to many researchers, innovation-driven economies are benefiting greatly from the proliferation of high-growthexpecting firms (Vallierea \& Peterson 2009). As per these researchers, high-growth entrepreneurs basically represent opportunity-motivated ones (Lecuna, Cohen \& Chavez 2017) because opportunity entrepreneurs are always keen for growth and recognise opportunities arising from innovative ideas, whereas necessity entrepreneurs intentionally avoid growth because their ultimate goal is survival (Capelleras et al. 2010; Valdeza et al. 2011).

Having recognised the strong contribution opportunity entrepreneurship makes to economic growth, many researchers question why innovation-driven economies are a fertile ground for high-impact entrepreneurs while others are not. The results have never been conclusive. Some attribute this to the well-entrenched entrepreneurial culture of these countries. The culture in developed economies encourages a significant portion of their population to become self-employed (Krasniqi 2009) and to focus mainly on technological breakthroughs that create added value in high-tech and knowledge-intensive sectors (Herrmann \& Kritikos 2013).

Apart from the culture, their success signifies the availability of quality institutions that promoteimpactfulentrepreneurship. Various studies have confirmed that fostering innovation and a robust entrepreneurial environment, which will make a meaningful contribution to the economy, is impossible without the prevalence of strong institutional frameworks and infrastructures (Feki \& Mnif 2016; Martinez-Fierro, BiedmaFerrer \& Ruiz-Navarro 2016; Mendonça \& Grimpe 2016). Thus, we can take the strong economic system that promotes new technology, increased pace of innovation and a short product life cycle (Baptista \& Thurik 2007) as a solid manifestation of the robust and supportive institutional frameworks that these countries have built over some years.

Moreover, the advantages of such institutions, culture and infrastructure are not limited just to the support that they provide to existing entrepreneurs; they also encourage the rise of many new wealth creators. As Autio and Fu (2015) argue, improved economic and political institutions boost formal entrepreneurship and reduce informal entrepreneurship tendencies. This implies that in well-structured economies, such as those in innovation-driven countries, the chance of obtaining subsistence entrepreneurship that relies on the informal sector is greatly limited. Thus, in developed economies, the U-shaped relationship between nascent opportunity entrepreneurship and economic development holds true, indicating the creation of many new ventures that focus mainly on innovation (Wennekers et al. 2010).

Research suggests that economies (innovation-driven economies) which foster the creation of firms that are inspired by innovation and high-growth potential see their actions lifting their GDP significantly (Aubry, Bonnet \& RenouMaissant 2015; Wong, Ho \& Autio 2005). This condition is further reinforced through favourable institutional frameworks, helping innovators to have a remarkable impact on economic growth attempts (Amaghouss \& Ibourk 2013).

Based on the above-mentioned information, we contend that innovative economies have higher propensities and capacities for producing TEAs that could meaningfully contribute to their GDP. Hence, we hypothesise a positive and strong relationship between the TEA rate and economic development as measured by GDP.

H1a: In innovation-driven economies, TEA and GDP are positively and strongly correlated.

Treating the entrepreneurial conditions of efficiency economies from the standpoint and vantage point of developed countries could lead to some terrible mistakes and may be considered as being in complete ignorance of the peculiarities of the two economic contexts. Indeed, the relationship between entrepreneurship and economic growth is stable across different categorisations of economies, but the level and magnitude of the impact differs significantly. For this reason, Vallierea and Peterson (2009) remarked that entrepreneurship matters, but it matters differently for emerging and developed countries.

Contrary to innovation-based economies, entrepreneurship in efficiency-driven economies is characterised by decreasing rates of self-employment (Acs, Desai \& Hessels 2008), high levels of volatility (Pfeifer \& Sarlija 2010), economic unpredictability (Ahlstrom \& Bruton 2010), low entrepreneurial culture (Lee \& Peterson 2000) and rampant numbers of necessity entrepreneurs who are mainly motivated by the lack of job opportunities or some other push factors (Yalcin \& Kapu 2008) as well as low growth prospects and low aspirations (Capelleras et al. 2010).

However, these economies are known for the abundance of untapped opportunities, although exploitation is a major problem (Yalcin \& Kapu 2008) because of the lack of strong and quality institutions that support the contributions of entrepreneurial initiatives (Ahlstrom \& Bruton 2010; Smallbone \& Welter 2001). In addition to this, entrepreneurship initiatives in these economies are constrained by the scarcity of resources (Ahlstrom \& Bruton 2010) and the finance required to carry out innovative projects (Smallbone \& Welter 2001). In these economies, although the venture creation speed is relatively fast, the growth is slow (Capelleras et al. 2010).

Consequently, it is concluded that starting and maintaining the survival of new ventures in less affluent, developing and transitional economies is burdensome (Yalcin \& Kapu 2008). As a result, the contribution of entrepreneurial start-ups to economic growth is not as strong as it should be (Aubry et al. 2015; Baptista \& Thurik 2007), while, sadly, the relationship between entrepreneurial activity and economic development is negative (Acs et al. 2008).

Contrary to these results, there are, however, authors who argue the other way around (see, for instance, Hashi \& 
Krasniqi 2011; Govindarajan \& Ramamurti 2011). These researchers contend that entrepreneurial activities in efficiency-based countries are contributing a great deal to economic growth and development, to the extent of influencing large multinationals in the developed world.

We believe that entertaining the two contrasting views is important in doing research of this nature. Therefore, it is hypothesised that a positive but weak correlation between new entrepreneurial start-up rates and GDP of efficiency economies exists.

H1b: In efficiency-driven economies, TEA and GDP exhibit a positive but weak correlation.

\section{The relationship between total early-stage entrepreneurial activity with perceived opportunity and entrepreneurial intention}

As stipulated in the GEM framework, TEA represents the share of adults in the total population of 18 to 64 years old, who are actively involved either in starting a new business (nascent entrepreneurship) or in managing a business that is less than 42 months old (Reynolds et al. 2005).

The prevalence of TEAs is found to be high in developing economies; however, their contribution is not as strong as their counterparts in well-developed economies (Kelley, Singer \& Herrington 2016; Wennekers et al. 2010).

As described in our previous discussion, the rates of early entrepreneurial activities differ from economies to economies, raising the question of what this difference means. According to many research findings, it reveals variations in countries' domestic productivity and economic growth (Aubry et al. 2015; Hashi \& Krasniqi 2011; Stel et al. 2005).

These findings imply that every single new entrant adds value in some form and helps countries to expand and boost their production. New firms, particularly those in transition economies, displace obsolete incumbents, fill existing market gaps and create new value (Stam \& Stel 2009). Moreover, such entrepreneurial activities are found to be essential to commercialise innovative technologies and for healthy development of the business population (Stel et al. 2005). Hence, any new addition always connotes a possible improvement in GDP and enhanced growth prospects.

However, there are several scholars who assert that the number does not matter, but the quality does. Shane (2009), who is a strong proponent of this claim, says countries need to focus on quality entrepreneurship that will make significant contributions to economic growth and, therefore, stresses the importance of focusing entirely on firms with high-growth potential. Mason and Brown (2013), concurring with his reasoning, have clarified policy measures that need to be taken to effectively support these firms. Yet, Shane's view was not insulated from criticisms. For instance, Daunfeldt, Elert and Johansson (2014) argued that policymakers should focus on conditions for new firm formation and early growth of new firms rather than targeting particular high-growth firms. They claimed that it is impossible for policymakers to know which firm will become a high-growth firm, ex ante.

Despite the inconsistencies with regard to where the focus must be, both research perspectives are in agreement on the importance of the rise and formation of new firms. Even Mason and Brown (2013) said policymakers cannot ignore support for start-ups, despite the strong support needed for high-growth firms. Therefore, countries aiming to expand and strengthen their economy are strongly advised to maintain an entrepreneurial environment that encourages citizens to pursue and allow their entrepreneurial ideas and intentions to materialise.

Identifying the factors that trigger individuals to pursue the entrepreneurial path is substantive to this discussion. We expect two factors to play a critical role with respect to this: an individual's ability to perceive opportunities and his or her entrepreneurial intention. It is solely when an entrepreneur possesses competencies such as the ability to perceive opportunities (Barazandeh et al. 2015) and the intention to act entrepreneurially (Río-Rama et al. 2016) that business ideas become a reality.

Johnson et al. (2015) argue that decisions to start and engage in entrepreneurial activities are not just driven by manic tendencies. Such activities are initiated by recognising an opportunity, which is apparently influenced by many factors (Wasdani \& Mathew 2014), and by having the commitment to materialise the said perceived opportunity (PO). Thus, we can say that hoping for a strong TEA rate without a significant percentage of people with the required capacity to see opportunities and the intention to pursue their entrepreneurial aspirations, is an illusion.

What then do we mean by opportunity perception and entrepreneurial intention? Let us first consider and explain opportunity perception and then the latter. Following the debate on the nature and source of entrepreneurial opportunity, opportunity perception becomes a very problematic concept. In this article, our intention is not to delve deep into the inconsistencies; thus, we have adopted the simplest definition. Opportunity perception is a perception of what can be done to earn a profit (Lewin 2012). It is also viewed as a process of identifying business opportunities, which normally represent market imperfections that give agents, entrepreneurs, the chance to obtain economic benefit by introducing new and/or improved products, the better to serve customer needs (Alvarez, Barney \& Anderson 2013).

Perceived opportunity triggers entrepreneurial actions through identifying what can be done in light of market gaps. With regard to the impact of PO, Herrington, Kew and Kew (2014) describe it as one of the two critical factors that force a person to consider starting their own business. 
Perceived opportunity, in the GEM conceptual framework, denotes 'the percentage of individuals aged 18-64 involved in any stage of entrepreneurial activity excluded who see good opportunities to start a business in area where they live' (Singer, Amorós \& Arreola 2015:23).

Global Entrepreneurship Monitor (GEM) reports consistently indicate that perceptions favouring the existence of good business opportunities are higher in factor-driven economies, while the strength of these perceptions declines as we move towards innovation-driven economies (Herrington et al. 2011). The findings suggest the existence of a large pool of people who could possibly take action to exploit the identified opportunity in efficiency countries compared to innovationbased countries. Therefore, we expect higher TEA rates in efficiency-driven countries than in innovation-driven countries because of the strong association between recognising opportunities and engaging in early entrepreneurial activities. Based on this assumption, we developed the following two hypotheses:

H2a: TEA is positively and strongly correlated with PO in efficiency-driven economies.

H2b: TEA is positively and weakly correlated with PO in innovation-driven economies.

The other major force that paves the way for a high TEA is strong entrepreneurial intention. The latter intention is defined as a conscious and planned resolve that drives the actions necessary to start a business (Thompson 2009).

Entrepreneurial intention (EI) does not refer to a whimsical desire to have a business; rather, it signifies a self-acknowledged conviction to set up a business and intentionally plan to do so at some point in the future (Thompson 2009). Thus, it can be said that a genuine intent is action oriented and this action is expected to result in nascent entrepreneurship. This is why entrepreneurial intention is depicted as a force that has a significant impact on new venture organising activities (Hopp \& Sonderegger 2015).

As presented by GEM, entrepreneurial intention refers to people who intend to start a business in the next 3 years; the intent is considered critical in the entrepreneurial process given its strong association with actual entrepreneurial behaviour (Herrington et al. 2014). And likewise, with the association discussed between PO and TEA, researchers found that entrepreneurial intention is higher among factordriven economies and lower among innovation-driven countries (Singer et al. 2015). Based on this elucidation, we propose the following two hypotheses to examine the relation between TEA and EI, both in efficiency- and innovationdriven economies:

H3a: TEA is positively and strongly correlated with EI in efficiency-driven economies.

H3b: TEA is positively and weakly correlated with EI in innovation-driven economies.

\section{Transforming an efficiency economy into an innovation economy: Entrepreneurship as enabler}

Countries always aspire to attain the next higher economic level. To achieve this substantial vision, they employ various macro- and micro-level economic and business strategies. In situations where there is a need to bring the majority of actors on board and to generate capital that would allow people at the bottom of the hierarchy to benefit, entrepreneurship remains as the most satisfactory solution (Bruton et al. 2015).

In addition to the job opportunity, increasing money flow and the sense of accomplishment that entrepreneurship provides at the individual level, it also plays a crucial role at national level through improving competitiveness among countries, promoting economic growth and increasing employment opportunities (Feki \& Mnif 2016). These virtues make entrepreneurship the best strategy and/or enabler compared to any other macro interventions aimed at transforming economic structures.

Entrepreneurship in efficiency-driven economies remains the major driver of economic growth (Stam \& Stel 2009). If we consider the BRICS countries (Brazil, Russia, India, China, and South Africa), which, with the exception of India, are good representatives of efficiency-driven economies, entrepreneurial activities at small and medium business level are contributing a great deal to employment creation and the GDP. In BRICS countries, small- and medium-scale enterprises (SMEs) are the major employers, absorbing 60\% of job seekers and making $42 \%$ of their GDP (Hoeppli 2013).

Yet the quality of entrepreneurship in efficiency-driven economies is a matter of concern for many. For years, the relationship between GDP and TEA reported to be U-shaped, wherein entrepreneurial activity tended to be higher for affluent and developing economies and less in transition economies (Pfeifer \& Sarlija 2010). This relationship implies an increasing and growing trend of entrepreneurial activities in developing countries because of an increase in necessitybased entrepreneurship, when innovation-driven economies take advantage of their strong institutions and infrastructure to promote opportunity-driven entrepreneurs (Wennekers et al. 2010). According to this relationship, efficiency economies apparently experience a decrease in self-employment and exhibit a negative relationship between entrepreneurial activities and economic development (Acs et al. 2008).

The question which then arises focuses on why the relationship is inverse in efficiency economies. The causes are too numerous to mention all. Institutional barriers (Hashi \& Krasniqi 2011), a preference for waged employment because of the higher opportunity cost of starting one's own business (Koellinger \& Thurik 2012), an unfavourable institutional framework (Ahlstrom \& Ding 2014), the lack of a welfare system that supports entrepreneurs (Chowdhury et al. 2015) and institutional instability (Ahlstrom \& Bruton 2010) are some of the factors that appear frequently. 
It is understood that transformation is impossible given all these deficiencies. Thus, many researchers call for an improvement in the overall entrepreneurial climate of transition economies (Koster \& Rai 2008) and in the transformation process, they stress the role of governments (Martinez-Fierro et al. 2016). Accordingly, they argue that governments need to take the central role in creating an entrepreneurial environment that promotes and fosters innovation (Maradana et al. 2017), high-growth potential entrepreneurs (Koster \& Rai 2008; Shane 2009) and exportoriented firms (Lecuna et al. 2017).

Moreover, it is the government's responsibility to develop supportive institutions that encourage a competitive business environment by reducing the burden imposed by formal institutions (Krasniqi \& Desai 2016), improving the social image of entrepreneurs (Barazandeh et al. 2015), ensuring corruption-resistant structures, strong property rights and reducing tax and administrative burdens (Chowdhury et al. 2015).

In this attempt, improving the quality of institutions stands out as a priority area. As argued by Autio and Fu (2015), economic and political institutional quality has a strong and meaningful relationship with the emergence and type of entrepreneurship. They claim that one standard deviation improvement in the quality of economic and political institutions could double formal entrepreneurship and reduce informal entrepreneurship by half.

The other frequently aired suggestion revolves around promoting innovation. According to this line of research, promoting innovation creates a comfortable platform for the generation of opportunity entrepreneurs who will make a meaningful contribution to economic growth (Aubry et al. 2015). In support of this claim, some suggest rechanneling entrepreneurship support programmes from necessity entrepreneurs to high-growth potential firms (Shane 2009) and encouraging policymakers to give due care to activities that help improve the quality of entrepreneurship and the emergence of ventures with strong growth prospects (Bruton et al. 2015; Koster \& Rai 2008).

In addition to the roles that governments could play, extant research also stresses the part played by existing entrepreneurial firms. The latter must be an integral part of the transformation endeavour and they must assume a leadership role (Aubry et al. 2015). It is suggested that private firms must be prepared to develop the capabilities that would allow them to differentiate their offerings and focus on strategic leadership that could help them build the competencies and resources necessary to compete and respond to the changes that the transformation brings (González-Corzo 2015).

Generally, researchers call for well thought out and controlled government interventions in order to create a conducive entrepreneurial ecosystem (Fuerlinger, Fandl \& Funke 2015) accompanied by a reallocation of capital and promotion of innovation (Bradley et al. 2012), careful management of money supply and interest rates (Galindo \& Méndez 2014) and revisiting of regulatory requirements (Gupta et al. 2014) as well as readjusting economic structure from one that places emphasis on efficiency and scope to one that appreciates effectiveness (Baptista \& Thurik 2007).

\section{Measurements and operationalising key terms Entrepreneurial activities}

We have adopted the GEM definition. Global Entrepreneurship Monitor defines entrepreneurial activities as:

... an output of the interactions of an individual's perception of an opportunity and capacity (motivation and skills) to act upon this and the distinct condition of the respective environment in which the individual is located. (Singer et al. 2015:20)

From the above definition, we can identify three major building blocks. The first one is the perception of opportunity, the second one is (having) the capacity and the last one is the environment in which the entrepreneur operates. Seamless integration of the three aspects of entrepreneurial activities could help develop an entrepreneurial atmosphere that is able to contribute effectively to the advancement of economies. As Morrison, Breen and Ali (2003) have argued, creating a growing small business requires a balanced alignment of the entrepreneur's intention, the abilities of the business and an opportunity environment.

\section{Economic growth}

In the same manner, GEM describes economic growth:

... as the result of individuals' (wherever they are located and regardless of whether they are self-employed or the size of the businesses) personal ability to identify and seize opportunities and that this process is taking place in the interaction with the environment. (Singer et al. 2015:18)

This basic assumption implies that any entrepreneurial activity occurring in the environment could exert a significant effect on the growth prospect of economies. Consistent with this claim, various research findings have confirmed the relationship between entrepreneurial activities and economic growth and development. Aubry, Bonnet and RenouMaissant (2015) have noted that changes in GDP are the indicators of new start-ups.

\section{Total early-stage entrepreneurial activity}

This includes individuals in the process of starting a venture and those running a new business less than 3.5 years old. In other words, it represents a 'percentage of individuals aged 18-64 who are either nascent entrepreneurs or ownermanagers of a new business' (Singer et al. 2015:24).

\section{Perceived opportunities}

'Percentage of individuals aged 18-64 involved in any stage of entrepreneurial activity excluded who see good opportunities to start a business in the area where they live' (Singer et al. 2015:24). 


\section{Entrepreneurial intentions}

'Percentage of individuals aged 18-64 involved in any stage of entrepreneurial activity excluded who are latent entrepreneurs and who intend to start a business within three years' (Singer et al. 2015:24).

\section{Gross domestic product}

It is an estimate of market throughput, adding together the value of all final goods and services that are produced and traded for money within a given period of time (Costanza et al. 2009).

\section{Methodology}

A challenging and crucial part of a study is deciding on the kind of research design that the research follows. Creswell (2014) claims that research designs provide specific direction for procedures. This claim entails that subsequent procedures and actions need to be in agreement with the chosen design to maintain the coherence and logical flow of ideas.

Throughout this article, we have followed a comparative research method, one that affords an opportunity to detect similarities and variances of two different groups (Mills, Bunt \& Bruijn 2006). As Mills et al. (2006) have argued, comparative analysis can include both qualitative and quantitative comparison of entities; its underlying goal is to search for similarities and variances. They assert that if researchers are able to deal with the limitations, such as construct equivalence, the method provides sensible and valid results.

We paid considerable attention to minimising the methodological limitations of this design. Pursuant to this we took maximum care while developing the two sets (efficiency-driven vs. innovation-driven economies). The selection was made on the basis of three major criteria. The first criterion was availability of relatively complete data within the selected time period; the second criterion was the level of economic development and, lastly, the comparability of GDP of the countries that make up the two sets. Based on these inclusion criteria, and as previously mentioned, we selected the United States of America, Great Britain and Germany to comprise the innovation-driven economies and China, Brazil and South Africa to form the efficiency-driven set.

The data for this study, as indicated previously, came from a GEM adult population survey data set and the UN database. As mentioned, we utilised the WEF countries' economic categorisation in order to form the two sets.

We measured the economic development by GDP, which is the most widely accepted measure of economic progress (Costanza et al. 2009), while the entrepreneurial dynamics were measured and are represented by PO, EI and TEA rates. Nine years (2006-2014) of data regarding entrepreneurial dynamics of countries were extracted from GEM adult population data sets, whereas the GDPs of countries were taken from the United Nations database.

A bivariate correlation analysis was employed to detect the relationship between TEA and GDP and TEA with PO, and the EI rating of countries as well as the hypotheses. Two separate correlation analyses have been performed for the two economic contexts; inferences are made based on the strength of the correlation in each scenario.

\section{Analysis, discussion and limitations}

The results of the analysis are discussed in two parts. The first part reports the results of the correlation of TEA and GDP and TEA with PO, and EI in innovation-driven economies and discusses the implication of the results. Similarly, the second part addresses the correlation results of the same variables in efficiency-driven economies and explains the implications. Correlations between the GDP and TEA, as well as measures of entrepreneurial tendencies (PO and EI) with TEA for innovation-driven economies, are listed in Table 1.

\section{Entrepreneurial context in innovation-driven economies}

As depicted in Table 1, the correlation between GDP and the measure of entrepreneurial activities is positive and strong. As we proposed, the correlation between GDP and TEA is significant at the $99 \%$ confidence interval and the relationship is very strong $(r=0.795, p<0.01)$. The result supports our first hypothesis (H1a) which states that TEA and GDP are positively and strongly correlated in innovation-driven economies. The result implies that any new entrepreneurial activity in an innovation economy will make a positive and strong contribution to economic development.

Our result agrees with the many research works that explored the relationship between the two factors (Aubry et al. 2015; Feki \& Mnif 2016; Stel et al. 2005; Yolaç 2015). As argued by Aubry et al. (2015), fluctuations in GDP in developed countries could be an indicator of early entrepreneurial activities.

The strong relationship between GDP and TEA also reflects the eutaxy of entrepreneurial activities developed in

TABLE 1: Correlations between gross domestic product and total early-stage entrepreneurial activity (TEA), and TEA with perceived opportunity and entrepreneurial intentions in innovation-based economies.

\begin{tabular}{llllll}
\hline Correlations & Variable & GDP & PO & EI & TEA \\
\hline GDP & Pearson's correlation & 1 & - & - & - \\
& Sig. (2-tailed) & - & - & - & - \\
PO & Pearson's correlation & 0.373 & 1 & - & - \\
& Sig. (2-tailed) & 0.061 & - & - & - \\
& N & 26 & 26 & - & - \\
EI & Pearson's correlation & $0.700^{*}$ & $0.658^{*}$ & 1 & - \\
& Sig. (2-tailed) & 0.000 & 0.000 & - & - \\
\multirow{2}{*}{ TEA } & Pearson's correlation & $0.795^{*}$ & $0.633^{*}$ & $0.863^{*}$ & 1 \\
& Sig. (2-tailed) & 0.000 & 0.001 & 0.000 & - \\
\hline
\end{tabular}

GDP, gross domestic product; PO, perceived opportunity; El, entrepreneurial intentions; TEA total early-stage entrepreneurial activity.

*, Correlation is significant at the 0.01 level (2-tailed). 
innovation-based economies. Furthermore, we believe that the strong presence of firms expecting high-growth (Vallierea \& Peterson 2009), a prevalence of innovative and knowledge firms (Zsuzsannaa \& Hermana 2012), the presence of favourable institutions (Amaghouss \& Ibourk 2013), a strong and quality institutional infrastructure (OECD 2008) and a well-developed entrepreneurial culture (Pinillos \& Reyes 2011) are contributing greatly to this.

Moreover, having noted the emphasis given to opportunity entrepreneurship (Valdeza et al. 2011) and the high prevalence of a voluntary mindset that encourages the development of innovative TEAs (Urbano \& Alvarez 2014), we expect this trend to continue.

The other result that deserves attention is the correlation among the three measures of entrepreneurial characteristics. As may be perceived from Table 1, the three factors exhibit positive and strong significant correlations among each other. Total early-stage entrepreneurial activity has a positive significant and strong correlation with EI and PO at a 99\% confidence interval $(r=0.863, p<0.01 ; r=0.633$, $p<0.01$, respectively). These results partially support our hypotheses (hypotheses $\mathrm{H} 2 \mathrm{~b}$ and $\mathrm{H} 3 \mathrm{~b}$ ), implying the existence of an inherent relationship between early entrepreneurial activities and entrepreneurial intention and PO, despite the lesser prevalence of EI and PO in innovation-driven countries as argued by Herrmann and Kritikos (2013).

However, our result supports prior findings such as the claim by Baumol and Strom (2007), who argue that only when individuals are able to notice and have the intention to exploit opportunities, entrepreneurial activities that reduce waste, improve macro-economic performance, increase productivity and enhance total welfare start to emerge.

The result also reinforces the notion that it is impossible to think in terms of a strong TEA rate when countries are characterised by an entrepreneurial atmosphere which is fragile and a populace which is incapable of acting entrepreneurially. More importantly, this relationship can be taken as the manifestation of the strong entrepreneurial culture enshrined in innovation-driven countries.

\section{Entrepreneurial context in efficiency-driven economies}

Table 2 presents the correlation between GDP and TEA rate of efficiency-driven economies. It also exhibits the correlation between factors identified as drivers of TEA (PO and EI) and TEA rate of efficiency-driven countries.

The correlation between GDP and TEA in efficiency-based countries reveals results similar to that of innovation-based economies, albeit the correlation is not as strong as it is in the latter. As shown in Table 2, TEA and GDP are significantly correlated at a $99 \%$ confidence interval and the correlation is moderate in terms of strength $(r=0.570, p<0.01)$. This result
TABLE 2: Correlation between gross domestic product and total early-stage entrepreneurial activity (TEA), and TEA with perceived opportunity and entrepreneurial intentions in efficiency-based economies.

\begin{tabular}{llcccc}
\hline Correlations & Variable & GDP & PO & EI & TEA \\
\hline GDP & Pearson's correlation & 1 & - & - & - \\
& Sig. (2-tailed) & - & - & - & - \\
\multirow{2}{*}{ EO } & Pearson's correlation & -0.195 & 1 & - & - \\
& Sig. (2-tailed) & 0.351 & - & - & - \\
\multirow{2}{*}{ TEA } & Pearson's correlation & 0.358 & $0.559^{* *}$ & 1 & - \\
& Sig. (2-tailed) & 0.079 & 0.004 & - & - \\
& Pearson's correlation & $0.570^{* *}$ & $0.405^{*}$ & $0.855^{* *}$ & 1 \\
\hline
\end{tabular}

GDP, gross domestic product; PO, perceived opportunity; El, entrepreneurial intentions; TEA total early-stage entrepreneurial activity.

*, Correlation is significant at the 0.05 level (2-tailed); **, Correlation is significant at the 0.01 level (2-tailed).

partially supports our hypothesis ( $\mathrm{H} 1 \mathrm{~b})$ which states that the correlation between TEA and GDP in efficiency-driven economies is positive but weak.

The result opposes findings that posit entrepreneurial activities in an efficiency economy as being less of a contributor to economic development (Acs et al. 2008; Aubry et al. 2015), but supports many other prior research findings (Hashi \& Krasniqi 2011; Stam \& Stel 2009; Zhang \& Duysters 2010) that stress the role of early entrepreneurial initiatives in economic development in transition economies.

Our result implies that despite the less accommodative entrepreneurial environment of efficiency-driven economies, every entrepreneurial initiative plays a positive and satisfactory role in the economic development endeavours of these countries. Nonetheless, the need for opportunity and/or high-growth entrepreneurs is still pressing and the contribution of the existing entrepreneurial activities cannot be undermined. They assist the economies to prosper by providing millions of jobs (Ayyagari, Demirguc-Kunt \& Maksimovic 2014), fostering reverse innovation (Govindarajan \& Ramamurti 2011), creating efficient utilisation of resources and developing positive externalities (González-Corzo 2015).

Yet comparing the result with innovation economies suggests the existence of considerable differences. We presume that the difference is rooted in factors inherent to the economic structure, institutional arrangements that are hostile for the growth of entrepreneurial attempts (Ahlstrom \& Bruton 2010), an immature entrepreneurship culture (Lee \& Peterson 2000), the proliferation of marginal entrepreneurs (Stel et al. 2005) and an underdeveloped welfare system for supporting entrepreneurs (Chowdhury et al. 2015). Generally speaking, the overall economic, entrepreneurial and societal environment is crippling entrepreneurs in efficiency economies, thereby preventing them from contributing much to the economic development there.

The other interesting result evident from Table 2 is that of the correlation among the three entrepreneurial factors. As can be inferred, each of these variables has positive and significant relationships among themselves. We found a strong positive 
correlation between EI and TEA at the 99\% confidence interval $(r=0.855, p<0.01)$. Similarly, the correlations between TEA and PO are significant and positive at the $95 \%$ confidence interval $(r=0.405, p<0.05)$. Both results provide partial support for hypothesis $\mathrm{H} 2 \mathrm{a}$ and fully support hypothesis H3a. The results imply that governments aiming to improve their TEA rate need to work on boosting the skills of citizens to perceive opportunity and foster an entrepreneurial intention that could encourage people to pursue entrepreneurial paths.

\section{Discussion, limitations and directions for future research}

In the existing literature, we came across many findings that explicate the relationship between entrepreneurship and economic development. Our study will attempt to build on this knowledge base and expand the knowledge frontier by examining the relationship taking two structurally different contexts and to identify areas where efficiency economies must improve to advance into the next economic stage.

Our analysis demonstrates that entrepreneurship and economic development are positively related both in efficiencyand innovation-driven contexts, although the magnitude of the relationship is much stronger in innovation-driven countries. In addition, we have established a strong correlation between TEA rates and factors leading to business formation. The result indicates that total early entrepreneurial activities are strongly associated with $\mathrm{PO}$ and entrepreneurial intention.

The correlations support the relevance of expanding institutions, platforms and systems that encourage identifying opportunities and instil the intention of pursuing an entrepreneurial route so that there are as many people as possible preferring to start their own business and create wealth for their country. Efficiency-driven economies need to enhance their TEA rate by training and exposing citizens to entrepreneurship and addressing structural constraints that cripple entrepreneurial intention.

Furthermore, if entrepreneurship is to contribute in its full capacity to economic growth, efficiency-driven economies need to pay due attention to the total entrepreneurial atmosphere. Improving the quality of entrepreneurship and fostering innovation have to be the central agenda. Creating a favourable institutional framework is the prerequisite for doing this (Amaghouss \& Ibourk 2013).

It is crucial to shift from scale, scope and experience into structures that intensify dependence on resources such as adjustment and effectiveness (Baptista \& Thurik 2007). However, promoting such kinds of entrepreneurial activities demands concrete actions from governments in developing and ensuring favourable institutional frameworks that encourage innovation.

Moreover, it is important to heed the necessity of revisiting regulatory requirements, normative dimensions and cultural- cognitive dimensions to encourage entrepreneurs and boost entrepreneurial activities (Gupta et al. 2014; Urbano \& Alvarez 2014). Careful attention needs to be paid to ensuring conducive regulatory systems; small business development and the enhancement of entrepreneurial skills, improving media coverage and the advancement of entrepreneurial confidence and developing entrepreneurial networks should be an area of special attention. Yet, the focus must not be placed simply on numbers because job creation and economic growth are not only driven by the number of entrepreneurs. The development programmes must focus on the formation of high-quality and high-growth companies (Shane 2009).

While we stress special attention must be given to highgrowth potential, it is also relevant to be aware of the possible side effects of such activities. As argued by Daunfeldt et al. (2014) and mentioned above, we do not know which firm will become a high-growth firm ex ante; hence, policymakers are advised to focus on formation of firms and early growth activities.

The impact of macro-level decisions on the proliferation of entrepreneurship, particularly entrepreneurship that emphasises innovation, must be considered. Central banks will have an essential role in promoting innovation and entrepreneurship through regulating the money supply and interest rates. Reducing the supply of money is expected to result in higher interest rates and promote savings, which will in turn aid financial institutions to maintain ample resources for entrepreneurs. Such monetary measures are expected to promote entrepreneurial behaviour and innovation. However, higher interest rates could result in a downside to entrepreneurship and investing in innovation (Galindo \& Méndez 2014). Hence, countries wanting to promote innovation and entrepreneurship should find a balance and use their monitory policy as a single effective tool.

If the aspiring entrepreneurs are to benefit from the growing economy, the growth should be inclusive and broad-based. This can be achieved only when the economic systems allow for reallocation of capital and promotion of innovation at various stages of the economy (Bradley et al. 2012). Thus, efficiency-based economies need to design various support mechanisms that encourage the distribution of capital through improved education, access to various social ties, accessible and affordable finance, and programmes that encourage and spur innovation.

While the role of government and its level of involvement are quite debatable, we too, concurring with the view of Fuerlinger et al. (2015), hold the view that the active involvement of governments in creating institutions and a conducive entrepreneurship ecosystem are relevant. Policy measures that promote research, autonomous higher education institutions emphasising innovation, business environment reforms which aim at nurturing entry and growth of innovative firms, financial systems that encourage 
innovation and a special focus on intellectual property rights protection must be put in place if these economies are to be transformed into the innovation-driven category (Fuerlinger et al. 2015; Herrmann \& Kritikos 2013). However, if government's involvement is not controlled and well managed, it will result in unintended consequences. Hence, we endorse the claim that stress:

... should be placed on diminishing government involvement as strong educational institutions flourish, the physical infrastructure improves, a supportive financial service sector develops and a favourable attitude towards entrepreneurship becomes convincingly positive. (Phan, Zhou \& Abrahamson 2010:186)

Despite its strengths, our study is limited in some respects. The first limitation emanates from the limited sample considered. We have included just six countries, three in each category, to study such a vast and complex relationship. Although we took maximum care to reasonably represent each economic context, we do not consider this classification as a perfect representation of the two contexts. Hence, we advise future researchers to consider a substantial number of economies to minimise the errors that may arise because of under-representation.

The complications involved in the relationship between entrepreneurship and economic development and in using entrepreneurship as a major development tool create a fertile ground for research. Our research examined merely the tip of this complex relationship by systematically focusing solely on innovation- and efficiency-driven economies. We believe that detecting the interaction of these variables in factordriven economies could provide some useful additional insights; hence, future researchers should consider adding factor-driven economies to the analysis and explicate areas of congruence and departures.

Another limitation of our research was the use of just one measure to represent economic development. Future researchers might detect the relationship either by using other competing economic development measures such as per capita income or a combination of other economic development measurements. In addition, we encourage using different variables, in addition to TEA, that are able to explain the entrepreneurship dynamics of economies.

The third limitation of our research emanates from the methods applied and data used. We used GEM data, which comprise survey data, and applied a bivariate correlation analysis to them. However, we are of the view that utilising multiple sources of data would give the investigator the chance to triangulate and obtain a complete and much clearer picture of the issues under consideration. Thus, future researchers are advised to tap into different data sources to substantiate the data they obtain from GEM. In addition, using multiple statistical tools could help examine the context from distinct perspectives and acquire rich insights from the data. Therefore, we recommend that future researchers should apply different econometric models to analyse the role of entrepreneurship in transforming economies and forces that drive entrepreneurial activities.

\section{Acknowledgements Competing interests}

The authors declare that there were no conflicts of interest during the writing of this article.

\section{Authors' contributions}

Both authors contributed equally to the writing of this article.

\section{References}

Acs, Z.J., Desai, S. \& Hessels, J., 2008, 'Entrepreneurship, economic development and institutions', Small Business Economics 31, 219-234. https://doi.org/10.1007/ s11187-008-9135-9

Ahlstrom, D. \& Bruton, G.D., 2010, 'Rapid institutional shifts and the co-evolution of entrepreneurial firms in transition economies', Entrepreneurship Theory and Practice 34(3), 531-554. https://doi.org/10.1111/j.1540-6520.2010.00373.x

Ahlstrom, D. \& Ding, Z., 2014, 'Entrepreneurship in China: An overview', International Small Business Journal 32(6), 610-618. https://doi.org/10.1177/0266242613517913

Albulescu, C.T. \& Tămăşilă, M., 2016, 'Exploring the role of FDI in enhancing the entrepreneurial activity in Europe: A panel data analysis', International Entrepreneurship Management Journal 12(3), 629-657. https://doi.org/10.1007/ s11365-015-0360-9

Alvarez, S.A., Barney, J.B. \& Anderson, P., 2013, 'Forming and exploiting opportunities: The implications of discovery and creation processes for entrepreneurial and organizational research', Organization Science 24, 301-317. https://doi.org/ 10.1287/orsc.1110.0727

Amaghouss, J. \& Ibourk, A., 2013, 'Entrepreneurial activities, innovation and economic growth: The role of cyclical factors', International Business Research 6(1), 153-162.

Aubry, M., Bonnet, J. \& Renou-Maissant, P., 2015, 'Entrepreneurship and the business cycle: The "Schumpeter" effect versus the "refugee" effect - A French appraisal based on regional data', The Annals of Regional Science 54(1), 23-55. https://doi.org/ 10.1007/s00168-014-0645-x

Auriol, E., Biancini, S. \& Paillacar, R., 2012, Intellectual property rights protection in developing countries, s.l., viewed from http://www.etsg.org/ETSG2012/ Programme/Papers.

Autio, E. \& Fu, K., 2015, 'Economic and political institutions and entry into formal and informal entrepreneurship', Asia Pacific Journal of Management 32(1), 67-94. https://doi.org/10.1007/s10490-014-9381-0

Ayyagari, M., Demirguc-Kunt, A. \& Maksimovic, V., 2014, 'Who creates jobs in developing countries?', Small Business Economics 43, 75-99. https://doi.org/ 10.1007/s11187-014-9549-5

Baptista, R. \& Thurik, A.R., 2007, 'The relationship between entrepreneurship and unemployment: Is Portugal an outlier ?', Technological Forecasting \& Social Change 74, 75-89. https://doi.org/10.1016/j.techfore.2006.04.003

Barazandeh, M., Parvizian, K., Alizadeh, M. \& Khosravi, S., 2015, 'Investigating the effect of entrepreneurial competencies on business performance among early stage entrepreneurs Global Entrepreneurship Monitor (GEM 2010 survey data) Journal of Global Entrepreneurship Research 5(18), 1-12. https://doi.org/10.1186/ s40497-015-0037-4

Baumol, W.J. \& Strom, R.J., 2007, 'Entrepreneurship and economic growth: Moderator comments', Strategic Entrepreneurship Journal 1, 233-237. https://doi.org/ $10.1002 / \mathrm{sej} .26$

Bradley, S.W., McMullen, J.S., Artz, K. \& Simiyu, E.M., 2012, 'Capital is not enough: Innovation in developing economies', Journal of Management Studies 49(4), 684-717. https://doi.org/10.1111/j.1467-6486.2012.01043.x

Bruton, G.D., Ahlstrom, D. \& Si, S., 2015, 'Entrepreneurship, poverty, and Asia: Moving beyond subsistence entrepreneurship', Asia Pacific Journal of Management 32(1), 1-22. https://doi.org/10.1007/s10490-014-9404-x

Capelleras, J.-L., Greene, F.J., Kantis, H. \& Rabetino, R., 2010, 'Venture creation speed and subsequent growth: Evidence from South America', Journal of Small Business Management 48(3), 302-324. https://doi.org/10.1111/j.1540-627X.2010.00296.x

Chowdhury, F., Terjesen, S. \& Audretsch, D., 2015, 'Varieties of entrepreneurship: Institutional drivers across entrepreneurial activity and country', European Journal of Law and Economics 40(1), 121-148. https://doi.org/10.1007/s10657-014-9464-x

Colovic, A. \& Lamotte, O., 2015, 'Technological environment and technology entrepreneurship: A cross-country analysis', Creativity and Innovation Management 24(4), 617-628. https://doi.org/10.1111/caim.12133

Costanza, R., Hart, M., Posner, S. \& Talberth, J., 2009, Beyond GDP: The need for new measures of progress, vol. 4, The Pardee Papers, Boston University The Frederick S. Pardee Center, Boston, MA. 
Creswell, J.W., 2014, Research design: Aualitatitive, quantitative and mixed research approaches, Sage, Riverside County, CA.

Daunfeldt, S.-O., Elert, N. \& Johansson, D., 2014, 'The economic contribution of highgrowth firms: Do policy implications depend on the choice of growth indicator?" Journal of Industry Competition and Trade 14(3), 337-365. https://doi.org/ $10.1007 / \mathrm{s} 10842-013-0168-7$

Driga, O., Lafuente, E. \& Vaillant, Y., 2009, 'Reasons for the relatively lowe entrepreneurial activity levels of rural women in Spain', European Society for Rural Sociology 49(1), 70-96. https://doi.org/10.1111/j.1467-9523.2008.00475.x

Feki, C. \& Mnif, S., 2016, 'Entrepreneurship, technological innovation, and economic growth: Empirical analysis of panel data', Journal of the Knowledge Economic 7(4), 984-999. https://doi.org/10.1007/s13132-016-0413-5

Fuerlinger, G., Fandl, U. \& Funke, T., 2015, 'The role of the state in the entrepreneurship ecosystem: Insights from Germany', Triple Helix 2(3), 1-26.

Galindo, M.Á. \& Méndez, M.T., 2014, 'Entrepreneurship, economic growth, and innovation: Are feedback effects at work?', Journal of Business Research 67, 825innovation: Are feedback effects at work?', Journal of
829. https://doi.org/10.1016/j.jbusres.2013.11.052

González-Corzo, M.A., 2015, 'Entrepreneurship in transition economies: Selected characteristics and relevant lessons for Cuba', Journal of Enterprising Culture 23(1), 91-115. https://doi.org/10.1142/S0218495815500041

Govindarajan, V. \& Ramamurti, R., 2011, 'Reverse innovation, emerging markets, and global strategy', Global Strategy Journal 1, 191-205. https://doi.org/10.1002/gsj.23

Guerrero, M., Urbano, D. \& Fayolle, A., 2016, 'Entrepreneurial activity and regional competitiveness: Evidence from European entrepreneurial universities', Journa of Technology Transfer 41, 105-131. https://doi.org/10.1007/s10961-0149377-4

Gupta, V.K. et al., 2014, 'Institutional environment for entrepreneurship in rapidly emerging major economies: The case of Brazil, China, India, and Korea International Entrepreneurship and Management Journal 10(2), 367-384. https:// doi.org/10.1007/s11365-012-0221-8

Hashi, I. \& Krasniqi, B.A., 2011, 'Entrepreneurship and SME growth: Evidence from advanced and laggard transition economies', International Journal of Entrepreneurial Behaviour \& Research 17(5), 456-487. https://doi.org/10.1108/135525511111 58817

Hechavarría, D.M., 2016, 'The impact of culture on national prevalence rates of social and commercial entrepreneurship', International Entrepreneurship and

Herrington, M., Kew, J. \& Kew, P., 2014, 2014 GEM South Africa report: The crossroads - A goldmine or a time bomb? University of Cape Town, Cape Town.

Herrington, M., Kew, J., Simrie, M. \& Turton, N., 2011, Global entrepreneurship monitor 2011 South Africa report, Graduate School of Business, University of Cape Town, Cape Town

Herrmann, B. \& Kritikos, A.S., 2013, 'Growing out of the crisis: Hidden assets to Greece's transition to an innovation economy', IZA Journal of European Labo Studies 2(14), 1-32.

Hoeppli, T., 2013, 'Economic conditions and business environment in BRICS', Professional Accountant 12-14.

Hopp, C. \& Sonderegger, R., 2015, 'Understanding the dynamics of nascent entrepreneurship - Prestart-up experience, intentions and entrepreneurial success', Journal of Small Business Management 53(4), 1076-1096. https://doi. org/10.1111/jsbm.12107

Johnson, S.L., Freeman, M.A. \& Staudenmaier, P.J., 2015, 'Manic tendencies are not related to being an entrepreneur, intending to become an entrepreneur,or succeeding as an entrepreneur', Journal of Affective Disorders 173, 154-158. https://doi.org/10.1016/j.jad.2014.10.049

Kelley, D., Singer, S. \& Herrington, M., 2016, GEM 2015/16 global report, Global Entrepreneurship Monitor, s.I.

Koellinger, P.D. \& Thurik, A.R., 2012, 'Entrepreneurship and the business cycle', The Review of Economics and Statistics 94(4), 1143-1156. https://doi.org/10.1162/REST_a_00224

Koster, S. \& Rai, S.K., 2008, 'Entrepreneurship and economic development in a developing country: A case study of India', The Journal of Entrepreneurship 17(2), 117-137. https://doi.org/10.1177/097135570801700202

Krasniqi, B.A., 2009, 'Personal, household and business environmental determinants of entrepreneurship', Journal of Small Business and Enterprise Development 16 146-166. https://doi.org/10.1108/14626000910932935

Krasniqi, B.A. \& Desai, S., 2016, 'Institutional drivers of high-growth firms: Countrylevel evidence from 26 transition economies', Small Business Economics 47, 10751094. https://doi.org/10.1007/s11187-016-9736-7

Lecuna, A., Cohen, B. \& Chavez, R., 2017, 'Characteristics of high-growth entrepreneurs in Latin America', International Entrepreneurship and Management Journal 13, 141-159. https://doi.org/10.1007/s11365-016-0402-y

Lee, S.M. \& Peterson, S.J., 2000, 'Culture, entrepreneurial orientation, and global competitiveness', Journal of World Business 35(4), 401-416. https://doi. org/10.1016/S1090-9516(00)00045-6

Lewin, P., 2012, viewed 31 March 2017, from https://organizationsandmarkets.com

Linan, F. \& Fernandez-Serrano, J., 2014, 'National culture, entrepreneurship and economic development: Different patterns across the European Union', Small Business Economics 42(4), 685-701. https://doi.org/10.1007/s11187-013 9520- $x$

Maradana, R.P. et al., 2017, 'Does innovation promote economic growth? Evidence from European countries', Journal of Innovation and Entrepreneurship 6(1), 1-23. $\mathrm{https}: / /$ doi.org/10.1186/s13731-016-0061-9
Martinez-Fierro, S., Biedma-Ferrer, J.M. \& Ruiz-Navarro, J., 2016, 'Entrepreneurship and strategies for economic development', Small Business Economics 47(4), 835-851. https://doi.org/10.1007/s11187-016-9738-5

Mason, C. \& Brown, R., 2013, 'Creating good public policy to support high-growth firms', Small Business Economics 40, 211-225. https://doi.org/10.1007/s11187011-9369-9

Matejovsky, L., Mohapatra, S. \& Steiner, B., 2014, 'The dynamic effects of entrepreneurship on regional economic growth: Evidence from Canada', Growth and Change 45(4), 611-639. https://doi.org/10.1111/grow.12055

Mendonça, J. \& Grimpe, C., 2016, 'Skills and regional entrepreneurship capital formation: A comparison between Germany and Portugal', Journal of Technology Transfer 41(6), 1440-1456. https://doi.org/10.1007/s10961-015-9444-5

Mills, M., Bunt, G.G. \& Bruijn, J.D., 2006, 'Comparative research: Persistent problems and promising solutions', International Sociology 21(5), 619-631. https://doi. org/10.1177/0268580906067833

Morrison, A., Breen, J. \& Ali, S., 2003, 'Small business growth: Intention, ability and opportunity', Journal of Small Business Management 41(4), 417-425. https://doi. org/10.1111/1540-627X.00092

Organisation for Economic Co-operation and Development (OECD), 1998, Fostering entrepreneurship, OECD Publications, Paris.

Organisation for Economic Co-operation and Development (OECD), 2008, OECD entrepreneurship review of Denmark, OECD Publishing, Paris.

Pech, R.M., 2016, 'Achieving the innovative edge in technology, engineering design, and entrepreneurship', Journal of Innovation and Entrepreneurship 5(6), 1-18.

Pfeifer, S. \& Sarlija, N., 2010, 'The relationship between entrepreneurial activities, national and regional development and firm efficiency - Global entrepreneurship monitor (GEM)-based evidence from Croatia', The Journal of Entrepreneurship 19(1), 23-41. https://doi.org/10.1177/097135570901900102

Phan, P., Zhou, J. \& Abrahamson, E., 2010, 'Creativity, innovation, and entrepreneurship in China', Management and Organization Review 6(2), 175-194. https://doi. org/10.1111/j.1740-8784.2010.00181.x

Pinillos, M.-J. \& Reyes, L., 2011, 'Relationship between individualist-collectivist culture and entrepreneurial activity: Evidence from Global Entrepreneurship culture and entrepreneurial activity: Evidence from Global Entrepreneurship Monitor data', Small
s11187-009-9230-6

Reynolds, P. et al., 2005, 'Global entrepreneurship monitor: Data collection design and implementation 1998-2003', Small Business Economics 24, 205-231. https://doi. org/10.1007/s11187-005-1980-1

Río-Rama, M.d.I.C.d., Peris-Ortiz, M., Álvarez-García, J. \& Rueda-Armengot, C., 2016, 'Entrepreneurial intentions and entrepreneurship education to University students in Portugal', Technology, Innovation and Education 2(7), 1-11.

Shane, S., 2009, 'Why encouraging more people to become entrepreneurs is bad public policy', Small Business Economics 33(2), 141-149. https://doi.org/10.1007/ s11187-009-9215-5

Singer, S., Amorós, J.E. \& Arreola, D.M., 2015, Global entrepreneurship monitor 2014 global report, Global Entrepreneurship Monitor, London.

Smallbone, D. \& Welter, F., 2001, 'The distinctiveness of entrepreneurship in transition economies', Small Business Economics 16(4), 249-262. https://doi.org/10.1023/ A: 1011159216578

Stam, E. \& Stel, A.V., 2009, Types of entrepreneurship and economic growth, UNUWIDER, Maastricht.

Stel, A.V., Carree, M. \& Thurik, R., 2005, 'The effect of entrepreneurial activity on national economic growth', Small Business Economics 24, 311-321. https://doi. org/10.1007/s11187-005-1996-6

Thompson, E.R., 2009, 'Individual entrepreneurial intent: Construct clarification and development of an internationally reliable metric', Entrepreneurship Theory and Practice 33(3), 669-694. https://doi.org/10.1111/j.1540-6520.2009.00321.x

Thornton, P.H., Ribeiro-Soriano, D. \& Urbano, D., 2011, 'Socio-cultural factors and entrepreneurial activity: An overview', International Small Business Journal 29(2), 105-118. https://doi.org/10.1177/0266242610391930

Tsai, K.-H., Chang, H.-C. \& Peng, C.-Y., 2016, 'Refining the linkage between perceived capability and entrepreneurial intention: Roles of perceived opportunity, fear of failure, and gender', International Entrepreneurship and Management Journa 12(4), 1127-1145. https://doi.org/10.1007/s11365-016-0383-x

Urbano, D. \& Alvarez, C., 2014, 'Institutional dimensions and entrepreneurial activity: An international study', Small Business Economics 42, 703-716. https://doi. org/10.1007/s11187-013-9523-7

Valdeza, M.E., Doktorb, R.H., Singerc, A.E. \& Danad, L.-P., 2011, 'Impact of tolerance for uncertainty upon opportunity and necessity entrepreneurship', Human for uncertainty upon opportunity
Systems Management 30, 145-153.

Vallierea, D. \& Peterson, R., 2009, 'Entrepreneurship and economic growth: Evidence from emerging and developed countries', Entrepreneurship \& Regional Development 21(5-6), 459-480. https://doi.org/10.1080/08985620802332723

Wasdani, K.P. \& Mathew, M., 2014, 'Potential for opportunity recognition along the stages of entrepreneurship', Journal of Global Entrepreneurship Research 2(7), 1-24. https://doi.org/10.1186/2251-7316-2-7

Wennekers, S., Stel, A.V., Carree, M. \& Thurik, R., 2010, 'The relationship between entrepreneurship and economic development: Is it U-shaped?', Foundations and Trends in Entrepreneurship 6(3), 167-237. https://doi.org/10.1561/0300000023

Wong, P.K., Ho, Y.P. \& Autio, E., 2005, 'Entrepreneurship, innovation and economic growth: Evidence from GEM data', Small Business Economics 24, 335-350. https:// doi.org/10.1007/s11187-005-2000-1 
Yalcin, S. \& Kapu, H., 2008, 'Entrepreneurial dimensions in transitional economies: A review of relevant literature and the case of Kyrgystan', Journal of Developmental review of relevant literature and the case of Kyrgysan', Journal of Developmental 00922

Yolaç, S., 2015, 'An empirical study regarding entrepreneurship in Europe and central Asia', Procedia - Social and Behavioral Sciences 195, 1097-1103. https://doi. org/10.1016/j.sbspro.2015.06.154
Zhang, Y. \& Duysters, G., 2010, Entrepreneurship development and the role of economic transition in entrepreneurial activities in China, UNU-MERIT Working Paper-036, United Nations University - Maastricht Economic and Social Research Institute on Innovation and Technology (MERIT), Maastricht.

Zsuzsannaa, S.K. \& Hermana, E., 2012, 'Innovative entrepreneurship for economic development in EU', Procedia Economics and Finance 3, 268-275. https://doi. org/10.1016/S2212-5671(12)00151-7 